\title{
Digital technologies will profoundly impact the way we grow and distribute food: here's how
}

\author{
Marie-Agnès Jouanjean ${ }^{1}$
}

Published online: 16 May 2019

(C) Bundesamt für Verbraucherschutz und Lebensmittelsicherheit (BVL) 2019

Automated tractors and dairy farms, drones or virtual fences; these represent the idea of the "digital farm", combining a range of high-tech devices, automated and linked through integrated systems. But they are only the tip of the iceberg of what the digital transformation of agriculture can mean for the way we grow, distribute and consume food.

At the core of the digital transformation of the agriculture and food sectors is the increasing capacity to produce, transfer and analyse data in ways that were previously neither technically nor financially feasible. Advances in data collection technologies, particularly via in situ and remote sensors, creating continuous or almost-continuous flows of data, have markedly increased the spatial and temporal resolution of agricultural data, while reducing the cost of gathering the information. Moreover, sensors are now cheaper and smaller and can be added to a range of devices. Combined with capacities in processing and cloud computing, agricultural data can now be re-used and aggregated from multiple sources to provide new insights. The Internet of Things (IoT) is also enabling the automation of repetitive tasks, and even more complex ones when combined with artificial intelligence (AI).

This datafication of agriculture is the process by which agricultural assets and production processes can be monitored, tracked, analysed and optimised. Datafication provides new ways to transfer knowledge, and in turn, enables the creation of new services upstream of the farm, supporting real-time and automated farm management (DeBoe and Jouanjean, unpublished results). On-farm data can be

Disclaimer The opinions expressed and arguments employed herein are solely those of the authors and do not necessarily reflect the official views of the OECD or of its member countries.

Marie-Agnès Jouanjean

Marie-Agnes.Jouanjean@oecd.org

1 OECD, Trade and Agriculture Directorate, 2, rue André Pascal, 75775 Paris Cedex 16, France useful for determining inputs or research and development, weather or pest alerts, or for financial services, while feedback loops using on-farm and off-farm data can be used to customise services for farmers, ${ }^{1,2}$ These feedback loops can also be used to support better agricultural policy making (DeBoe and Jouanjean, unpublished results).

While the digital transformation of agriculture holds considerable promise, it also raises new challenges and concerns among stakeholders. While there are many incentives for producers to embrace the use of digital technologies, they will influence the sector in many ways; with different impacts upon various stakeholders, and it is unclear at this stage who will ultimately benefit and whether new divides will be created. Many of the new technologies are also "black boxes" for producers, and many are still at a rather early stage of development.

While physical digital connectivity is the key first step, the regulatory environment is critical in determining the capacity and willingness of the agricultural sector to produce and use data for decision-making and value creation. There is thus a need for greater clarity about the regulatory environment governing the use of digital technologies. As for any uncharted technological territory, the regulatory environment might not be in place, or may not be adequate. At present, there are many questions about who owns the data; who can access and use it; the consequences for competition and distribution of value added among stakeholders in the chain; and who is responsible where the technology fails. There is not yet any globally shared answers to these questions and governments are only at the early stages of dealing with them. But these uncertainties can undermine the uptake of digital technologies in agriculture, and may even have unintended consequences.

\footnotetext{
1 Jouanjean MA (2019) Digital opportunities for trade in the agriculture and food sectors. OECD Food, Agriculture and Fisheries Papers 122, OECD Publishing, Paris.

${ }^{2}$ Wolfert S, Ge L, Verdouw C, Bogaardt MJ (2017). Big data in smart farming - a review. Agric Syst 153:69-80.
} 
Beyond the farm, data can feed into the rest of the value chain, revolutionising the integration of agro-food value chains, and potentially the way value is created. Digital technologies provide new opportunities, from further product differentiation and access to new markets, to new ways to conduct transactions. Moreover, digital technologies are bringing new and more efficient traceability, contributing to enhancing the integrity of food products along the supply chain.

Some leading companies across the food supply chain, food industry and retailers (including e-commerce), are investing in testing the potential of new technologies for better traceability, including distributed ledger technologies (or, blockchain), to maintain secure digital records and improve the traceability of foodstuffs. The aim is to improve current traceability and data management processes across the complex network of farmers, brokers, distributors, processors, retailers, regulators, and consumers. For food safety, blockchain technologies are seen by some as able to facilitate and fast-track investigations and trace outbreaks back to specific sources, potentially reducing them from weeks to seconds. While digital technologies will never eliminate all food risks, they should improve the speed and efficacy of the response, reducing costs and limited damage.

Consumers are also increasingly interested in knowing how their food is being produced and there is increasing demand for more transparency throughout the supply chain. This is evidenced by the uprise of organic food, which is now reaching scale and mainstreamed by large retailers. The promise of new flows of information provided by digital technologies throughout the supply chain will help consumers translate their preferences into purchasing decisions, with a new degree of confidence.

All of these opportunitites rely on sharing data within and between the public and private sectors, but also on enabling cross border data flows. The regulatory environment will have to enable ways to access and integrate information, both from public and private sector, and at the same time respect a range of concerns about data access and use, from privacy concerns to trade secrets. Creating trust in the regulatory environment is of particular importance both for consumer and producer confidence. But creating trust in the technology itself is also of particular importance as there could be a risk of backlash if the digital technologies are not transparent and trustworthy. Beyond the hype, it is important to acknowledge that many of those technologies are still in their infancy, and it is sometimes difficult to differentiate marketing from real innovation. Without strangling innovation, governments should find ways to ensure that new technologies are used according to certain standards, to ensure security and quality of services. There is a need to manage expectations about what the technology can deliver, to build understanding of and manage potential risks, in order to create the environment of trust that will allow the significant benefits of digitalisation for agro-food to materialise.

Publisher's Note Springer Nature remains neutral with regard to jurisdictional claims in published maps and institutional affiliations. 